\title{
Tempo e performance no trabalho docente
}

\author{
Time and performance in the teaching work
}

Elaine Conte*

Centro Universitário La Salle

Resumo A emergência de um tempo que é performativo, embora interaja com as dimensões humanas irrestritas ao aspecto formal do processo de formação (Bildung), também revela uma racionalidade instrumental que trata do passado como meio para legitimar o agir técnico do presente. O ensaio repensa, de um ponto de vista filosófico, o tempo próprio da formação docente levando em consideração a performance como pressuposto inevitável à ação linguístico-expressiva no mundo. Cada vez mais, o tempo surge como um fator importante à performance, uma vez que o trabalho docente exige atitudes de criação e de reconhecimento de valores receptivos à alteridade. É necessário pensar o tempo como inseparável de sua linguagem, na medida em que fornece novas possibilidades de abertura crítica e renovação do trabalho educativo, conferindo novos sentidos ao agir performativo.

PALAVRAS-CHAVE: Tempo humano, performance, tecnologias, formação docente.

Abstract The emergence of a performative time, although it interacts with the unrestricted human dimensions to formal aspect of the formation process (Bildung), also reveals an instrumental rationality that treats the past as a means to legitimize the present technical act. The study rethink, from a philosophical point of view, the proper time of teacher training considering the performance as a precondition to the inevitable linguistic-expressive action in the world. Increasingly, the time appears as an important factor to performance, since the teaching work requires the creation attitudes, of recognition receptive values to otherness. Is necessary to think the time as inseparable from its language, according as provides new possibilities for critical aperture and renovation of educative work, giving new directions to performative act.

KEYWORDS: Human time, performance, technology, teacher formation. 


\section{Tempo e performance como horizontes abertos}

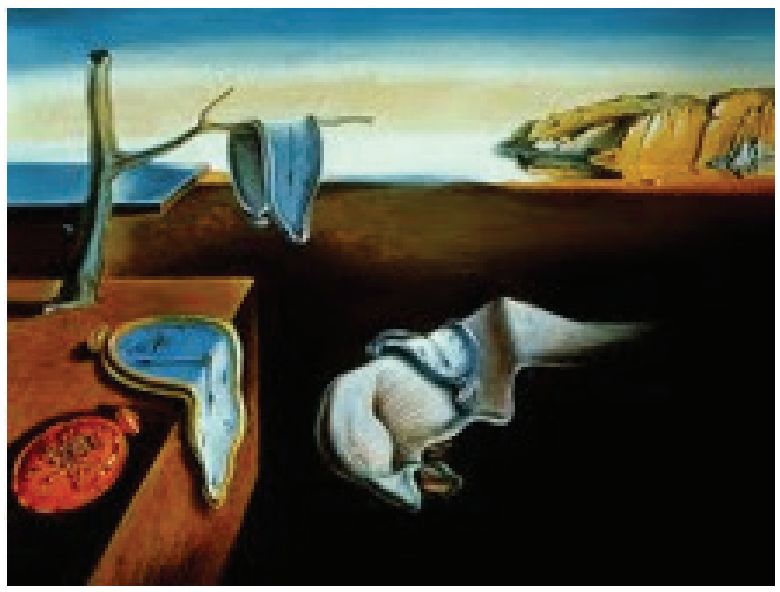

Salvador Dalí: A persistência da Memória (1931)

A questão do tempo é uma preocupação humana mobilizada na obra de arte de Salvador Dalí, mostrando a flacidez dos relógios dependurados e escorrendo, como se processa e atua a força vital, criadora e plástica, tal qual a compreensão do tempo na modernidade, que desmancha a realidade. O quadro de Dalí mostra um tempo flexível, maleável, relativo, em que passado e presente se fundem. Tal produção artística reproduz uma atmosfera inquietante de linguagem que funde sonho e realidade, dando a ideia de que o tempo rompe com as percepções convencionais da realidade. A arte denota um processo de fazer e obrar que contribui muito para desinstalar lugares fixos no campo das humanidades, aparecendo o movimento na imagem, efeitos das rupturas e descontinuidades de linguagens (referentes ao outro da razão), que passaram a expressar as mudanças temporais produzidas pelo progresso da tecnologia ${ }^{1}$ (manifestado no ícone da velocidade). A performance expressa esse universo intenso da linguagem artística inscrita no mundo e assume o sensível como presença, aparição multifacetada, que não pode ser dita a partir de um conceito linear, pois é um universo cuja plasticidade se oferece ao mundo como permanente abertura ao diálogo. A performance, enquanto constituição antropológica, é um produto do humano enraizado na concretude do mundo que restabelece as conexões com o outro, com o tempo, com a natureza, com a sociedade, com o mundo, e necessita da participação do outro para realizar-se. Trata-se do tempo tal como é vivido, do tempo relacional com o outro da formação intersubjetiva, e não do tempo cronológico da percepção limitada da vida humana, expresso em termos de datas precisas (MOURA, 2007). Daí que o tempo da formação é o tempo do reconhecimento do outro como experiência temporal que nos é dado enquanto educação.

Desde Plotino, o entendimento do tempo assume a marca do constante progresso da novidade contida na diferenciação da vida. Para Aristóteles (1996), o tempo é pensado e vinculado ao movimento contínuo, às mudanças e deslocamentos de estados das coisas e dos seres, como produto de ações humanas livres. Na moderni- 
dade surge a visão do tempo como um futuro possível, cujas alternativas o homem vai determinando desde o presente, o que o vincula ao conceito de progresso e de história. Podemos dizer que o tempo aparece como um instante da percepção sensível, cheio de ambivalência, plasticidade, um movimento que demanda corporeidades que se relacionam performaticamente. Do ponto de vista de Arendt (1972), para o homem que vive sempre no intervalo entre o passado e o futuro, o tempo não é um contínuo, um fluxo de ininterrupta sucessão. E é no espírito de um jogo dialético passado-futuro-presente que vinculamos a ideia de performance como ação linguística que necessita da adesão dos outros para existir (é um processo de autoformação e de criação transformadora). $\mathrm{O}$ termo performance, como um conceito correlato ao de racionalidade comunicativa, instaura a ação performática que é simultaneamente voz, gesto e corpo, isto é, pragmática, estética e expressiva. A ideia de uma racionalidade comunicativa remete às diversas formas de desempenho discursivo, na medida em que está ligada à ação comunicativa do homem no mundo. A performance é uma atitude realizativa, global e artística, por revelar que o sujeito ao se expressar dispõe de saberes e atos de comunicação que satisfazem os critérios de discurso, ao mesmo tempo, do mundo objetivo, social e subjetivo (HABERMAS, 1987).

A educação é permeada por uma infinidade de problemáticas que remetem ao campo da performance como o tempo de indeterminação humana, pois nem sempre precisamos confiar antropologicamente em nossas tradiçôes (HABERMAS, 1987). Justamente porque,

A educação é um acontecimento temporal, que se apresenta complexo, incontrolável e necessário. Não há garantia possível da ação correta que assegure a obtenção do fim desejado, porque não há mais um modelo de natureza humana para orientar a ação, como ocorre na tradição clássica. [...] O caráter incontrolável da educação não significa desorientação, mas é apenas o reconhecimento da finitude humana que agora faz suas exigências. (HERMANN, 2001, p. 129)

Em razão da liberdade humana não há ciência capaz de desvendar os mistérios do processo de educação, de forma a domar as incertezas e imperfeições do saber humano, uma vez que o enigma da formação não se deixa apreender inteiramente pela organização do trabalho, dos métodos de ensino e do currículo. Entretanto, a preocupação com a arte de bem ensinar sempre foi uma das motivações da docência. O fato é que há uma disritmia entre os tempos predefinidos da matéria (aulas em que se explica tudo de forma disciplinar, menos a própria vida), os tempos de aprender dos educandos e de ensinar dos mestres. Educar exige fina sensibilidade para lidar com o tempo performativo humano (respeitando cada sujeito na sua incompletude e promovendo o processo dialógico contra a alienação), como convívio formador do desenvolvimento coletivo e das aprendizagens. É o reconhecimento do caráter ativo, histórico, criativo, cultural e humano de aprender que nos obriga a não esquecer que as aprendizagens se constroem em contextos múltiplos e variáveis ao longo da vida, que podem ser discutidos pelas inter-relações e interfaces entre educação, tecnologia e linguagem, sob a dimensão do tempo performativo na multiplicidade da vida. Neste debate hermenêutico vamos encontrar uma percepção das mutações do tempo pre- 
sente e das mais variadas formas de interpretação desse processo de esfacelamento de uma ordem estabelecida, que tem a emergência da pluralidade como um discurso eminentemente contemporâneo.

\section{A performance como presença e tempo da formação}

Vivemos o tempo que colocou em cena as revoluções tecnológicas em que a contingência reativa aos momentos vividos, se tornou uma transitoriedade que se desdobra na companhia dos outros nas interlocuções de mundos. Seu protótipo foi o Iluminismo filosófico (a maioridade do sujeito no uso de sua razão) que inaugurou a crença no progresso científico, político, social, moral e econômico contra o obscurantismo do passado, trazendo a ideia de superioridade do presente em relação ao passado. Fazendo uma analogia com o tempo enquanto deslocamento de sentido, podemos dizer que efetivamente, o homem passa de relógio do mundo (potencialmente criativo) a ser uma simples peça de engrenagem deste grande relógio. No mundo cartesiano, o homem guiado pela certeza do conhecimento torna-se incapaz de recriá-lo e nessa dissolução técnica com o mundo o sujeito fica preso a sua própria razão instrumental. Nesse contexto, Habermas (1989) revela uma preocupação com as redes de comunicação que avançam como uma racionalidade sistêmica na produção de imagens, transformando o conhecimento e a arte em mercadoria. $\mathrm{Na}$ atualidade, os próprios conteúdos culturais encontram-se virtualizados nas redes de informações, sendo que a ciência e a técnica, transformadas pelas tecnologias virtuais, modificam o mundo do trabalho em atividades cada vez mais abstratas, concentradas em serviços que transformam o conceito de mera produção no binômio trabalho e interação (MARTINI, 2007). A cultura que vive nessa forma de comunicação parece não exigir mais a necessidade de um processo de formação mediado dialogicamente pela presença do educador.

Partimos da constatação de que o nosso acesso ao mundo já está impregnado por motivações linguísticas, da mesma forma como o mundo é criado esteticamente pelas palavras, elas constituem o meio da ação pedagógica (que tem presença no mundo, pois preserva e transforma o conhecimento). Tal como observa Habermas (2004, p. 38-39), "a linguagem e a realidade interpenetram-se de uma maneira indissolúvel para nós. Cada experiência está linguisticamente impregnada, de modo que é impossível um acesso à realidade não filtrado pela linguagem”. O diálogo revela a presença dos sujeitos nos quais o pensar se faz algo vivo. Contudo, identificamos o ato pedagógico como um ato expressivo, que não pode ser abstraído da realidade instrumentalmente, mas precisa levar em consideração a natureza humana da expressão, do corpo, da presença que joga, linguisticamente, e interage. Podemos afirmar que a performance está mais orientada pela ação comunicativa, sendo que um dos seus traços principais é o seu caráter autoral, de ação evidente. Com efeito, a performance é um comportamento restaurado e vivo sempre ligada à presença, ao corpo, ao cultural, marcando identidades nas circunstâncias transitórias da existência pessoal, social, política, tecnológica. Do ponto de vista de Paul Zumthor (2007, p. 59), a performance é um modo vivo de comunicação poética, um "termo antropológico e não histórico, relativo, por um lado, às condições de expressão, e da percepção, por outro, performance designa um ato de comunicação como tal; refere-se a um momento tomado como pre- 
sente. A palavra significa a presença concreta de participantes implicados nesse ato de maneira imediata”. Em outros termos, a performance abre caminho à intervenção no mundo. "É por isso que o educador progressista, não apenas deve ensinar muito bem a sua disciplina, mas desafiar o educando a pensar criticamente a realidade social, política e histórica em que é uma presença" (FREIRE, 2000, p. 21-27). Em uma formulação mais ampliada, falamos da força da performance como formação na dinâmica de uma prática educativa radical, estimuladora da curiosidade crítica, à procura das razões de ser especificamente humana, que se funda na ação interdisciplinar.

[...] mais do que um ser no mundo o ser humano se tornou uma presença no mundo, com o mundo e com os outros. Presença que, reconhecendo a outra presença como um 'não-eu', se reconhece como 'si própria'. Presença que se pensa a si mesma, que se sabe presença, que intervém, que transforma, que fala do que faz mas também do que sonha; que constata, que compara, avalia, valora, que decide, que rompe. (FREIRE, 2000, p. 51)

Trata-se, aqui, de pensar a performance do professor não como ação solitária, mas como uma prática restituída e solidária, que incide necessariamente sobre o real e, ao mesmo tempo, um movimento no qual entramos no jogo da linguagem, numa formação incessante que se constrói no momento da interação face a face ${ }^{2}$. De acordo com Zumthor (2007, p. 67), "a performance é ato de presença no mundo e em si mesma", ato no qual o próprio mundo se concretiza. De certo modo, "a palavra significa a presença concreta de participantes implicados nesse ato de maneira imediata. Nesse sentido, não é falso dizer que a performance existe fora da duração" (ZUMTHOR, 2007, p. 50). Na verdade, a performance atualiza virtualidades, rearranja o tempo de inacabamento, fazendo passar ao ato a força originária do diálogo formador que descentra e ao mesmo tempo reintegra a multiplicidade de sentidos humanos na plenitude. Daí a importância de um trabalho crítico sobre a performance numa zona fronteiriça que subsidia a diversidade dos modos de olhar e pensar o mundo, o que equivale a continuar sua criação ininterrupta. Em performance a figura do professor é o instrumento de realização da atuação humanizadora e sensível, da criação da própria arte de educar como possibilidade para estudar e aprender, pela ação de comunicar impregnada de sentidos intersubjetivos. O trabalho educativo é um processo permanente e prazeroso quando desperta a curiosidade e as práticas de linguagens artísticas que fazem transmutar a diversidade em riqueza, permitindo reconhecer o outro (nas diferenças enquanto intensidade da presença). Nas palavras de Freire (1996, p. 63-64), "estar no mundo sem fazer história, sem por ela ser feito, sem fazer cultura, sem 'tratar' sua própria presença no mundo, sem sonhar, sem cantar, sem musicar, sem pintar [...], sem aprender, sem ensinar, sem ideias de formação, sem politizar, não é possível", pois é no reaprender performativo que a educação se alicerça. Nesse contexto, desde a presença que desperta entusiasmo instala-se o círculo da compreensão com seus alcances educacionais, como movimento constitutivo da experiência estética (autoformativa e transformadora no sujeito), que não se esgota na subjetividade, nem na objetividade, mas se dá na e com a experiência da alteridade linguística (no jogo de performances).

Para Habermas (1990), a emergência de um contexto pós-metafísico, torna-se uma característica inevitável do nosso tempo performativo, pois fora do mundo 
prático não temos um acesso privilegiado à ordem da razão (metafísica) ou à instância decisória (subjetividade). Em todo caso, da análise da linguagem (guinada linguística), chega-se à linguagem como prática social (guinada pragmática) e interpretativa (guinada hermenêutica), como modo de performar, compreender e dizer as condições de vida no mundo (ROHDEN, 2002). Daí que o conceito de racionalidade comunicativa pode ser tomado como sinônimo de agir performativo, porque ele constitui o entendimento racional a ser estabelecido entre os participantes de um processo dialógico que se dá através de múltiplas linguagens e razões, voltados para a compreensão de fatos do mundo objetivo, de normas e de instituições sociais ou da própria noção de subjetividade. Em função disso, os sentidos da racionalidade humana na ambivalência da dimensão performativa (e tecnológica) atrela uma linguagem descentrada do conhecimento agindo em nós para além da cronologia do tempo, ou seja, numa temporalidade do agir comunicativo. Isso porque evidencia a complexidade da vida como luta e paradoxo, que supera a unidimensionalidade da técnica, numa atitude que incorpora a vivência plena das emoções e com elas nos permite recriar constantemente nosso mundo atual.

Hoje, a constituição formativo-educacional do ser humano no mundo depende cada vez mais daquilo que aprendemos, da nossa formação, da nossa capacidade de produzir ideias, do nosso modo de viver o tempo livre e da nossa sensibilidade estética. O tema da formação está entrelaçado com a questão da performance, que é, ao mesmo tempo, aprendizado e formação, um formar-se a si próprio que implica numa transformação. Os ideais formativos para a vida em nossa sociedade estão relacionadas com nosso tempo e nossa história que interroga continuamente sobre os sentidos do educar. O tempo pertence à concepção moderna de mundo, a sua presença e restauração é conhecida como performance. Segundo Ricoeur (1975, p. 30), a imagem do tempo está inscrita no tecido da vida cotidiana, sendo inúmeras as maneiras de fazer a história que marcam ou selam o tempo. Nesta abordagem, expressar o tempo é criar incontáveis faces (artefatos simbólicos) e um impressionante repertório de relações com o outro e com o mundo, de exigências éticas, de práticas sociais, de desafios de poder. Enfim, o tempo é polêmico e multifacetado, um dispositivo das relações humanas, vital para o sujeito dotar-se de identidade e orientar suas ações. Mas com a imposição de uma representação temporal, em que os significados de continuidade e perpetuidade assumem o primeiro plano da qualificação temporal e o todo se sobrepõe às partes, gera-se a precariedade das ações humanas. O tempo patológico (vazio de significado) cultiva o estresse da monotonia do tempo que não passa, pois está alienado na perda do sentido das ações e da qualidade dialética do vivido. Tal contexto causa o aniquilamento dos valores atribuídos aos agentes históricos no tempo, tal como vivido, aqueles existenciais, como a transitoriedade e a finitude.

Nesse processo, predomina uma percepção do tempo, na qual não mais se tem tempo para ouvir o outro ou desenvolver uma autorreflexão prática como horizonte de expectativas, visto que estamos atrelados a um presente perpétuo, que se desdobra em esforços para se autolegitimar. Da mesma forma, temos de ouvir, naquilo que o sujeito diz, o que ele não diz, mas que constitui igualmente os sentidos de suas palavras, gestos, ações e expressões (DUARTE, 2008). A racionalidade performativa é antinômica, permeada de impulsos estéticos, de sensibilidade e pode ser tempora- 
lizada no encontro provocador com o outro sujeito, sendo por si desestabilizadora do sentido único e marcada pela dinâmica da abertura de compreensão e entendimento do mundo. A formação pedagógica ampliada nos elementos artísticos da linguagem performativa interage na leitura social e fala através de vozes outras negligenciadas pela lógica racionalista. Ao aproximarmos performance e tempo num jogo de limiar linguístico-expressivo nos damos conta de que:

O tempo já não é mais, primariamente, um abismo a ser transposto porque divide e distancia, mas é, na verdade, o fundamento que sustenta o acontecer, onde a atualidade finca suas raízes. A distância de tempo não é, por conseguinte, algo que tenha que ser superado [...]. $\mathrm{Na}$ verdade trata-se de reconhecer a distância de tempo como uma possibilidade positiva e produtiva do compreender. (GADAMER, 1998, p. 445)

Pode-se alegar com Tardif e Lessard (2005) que lidar com condicionamentos e enfrentar situações transitórias e variáveis na profissão docente é algo formador, pois a questão do saber está situada no contexto mais amplo do estudo da docência, de sua história recente e de sua situação dentro da escola e da sociedade, que se desdobra num espaço social e num tempo histórico de autoconstrução e transformação. A rigor, Tardif e Lessard criticam o paradigma que reduz o saber dos professores a processos psicológicos (o mentalismo) a visões tecnicistas e a concepções sociológicas tradicionais, que associam os educadores aos reprodutores das estruturas dominantes, para explicitar melhor cada um desses paradigmas e as suas influências em diferentes tempos/espaços da educação.

\section{Ressignificando a performance na educação}

A partir da redescoberta do fôlego humanista, que motivou as investidas estéticas, científicas e técnicas dos tempos modernos, emerge um tempo em que as performances tornam-se grandes referências no processo de construção do mundo, colocando em jogo as instâncias articuladoras da sensibilidade crítica e da linguagem criativa como desafios ao exercício das práticas pedagógicas. Ao que tudo indica, a comunicação promove a abertura temporal do sujeito, na qualidade de reintroduzir as ações educativas no âmbito social. "À consciência moderna do tempo deve-se também a definição de que a práxis está orientada para o futuro e produz o novo. Ao tomar a iniciativa, aquele que age transcende todas as determinações dadas e constrói um novo começo" (HABERMAS, 1990, p. 457). A relação de horizontalidade e provisoriedade entre tempo e performance revelam mais do que a simples e linear acumulação de habilidades/competências, mas o reconhecimento das dimensões comunicativas plenas de sentido e significação e, por isso, ativas, criativas, múltiplas, fluidas, contraditórias, colaborativas e sempre incompletas do agir humano. Como sugere Hermann (2005, p.14, grifo nosso), a "emergência da estética aponta que as forças da imaginação, da sensibilidade e das emoções teriam maior efetividade para o agir do que a formulação de princípios abstratos e do que qualquer fundamentação teórica da moral". O conhecimento é um ato de criação estética que não se percebe passivamente por meio dos sentidos ou da comunicação, mas se constrói, ativamente, pelos sujeitos na experiência provocativa com os outros, num ato que performa a realidade. 
A questão da performance na formação docente coloca em xeque os saberes finitos, inexpressivos e determinados da profissão, bem como as ilusões acerca da aprendizagem como algo isolado, linear, cumulativo e disponível à avaliação empírica, para tratar do processo de aprender marcado pelos jogos de linguagem (que envolve corpo, gesto, imaginação) e pela motivação performativa (ato ilocucionário). Parafraseando Austin (1990), podemos dizer que o êxito da comunicação corresponde ao êxito da própria formação e ação pedagógica. Os atos de fala performaticamente utilizados não descrevem ou exteriorizam uma concepção de tempo, eles a constroem no interior deste processo em que falar algo é criar, é constituir aquilo de que se fala, quando se fala. $\mathrm{O}$ tempo tornou-se um instrumento de ação e também um recurso de controle sobre os homens, pois em um tempo previsível, submetido à materialidade da organização institucional (perda da transcendência), e selado por uma objetividade estratégica, temos a ameaça constante de esvaziamento dos processos (per)formativos mobilizados no mundo. Foi-se o tempo em que o professor ao atingir a graduação em Pedagogia considerava-se formado/pronto, já possuindo os conhecimentos totalizadores do ofício, como diria Freire (1996), a comunicação é transformadora e requer que continuemos abertos às novas reconfigurações de sentido, como algo constitutivo do diálogo na educação. Daí que as novas sensibilidades transformadas pelas tecnologias digitais propõe abarcar a complexidade das conversações com o mundo, suscitando nossa curiosidade epistemológica. A parte mais interessante é que não se pode imaginar um ponto terminal para aprender e as tecnologias digitais virtuais aguçaram esta percepção de renovar-se indefinidamente. Com a velocidade das tecnologias e sua temporalidade intensiva e fugaz, impõem-se novos ritmos e dimensões à profissão docente tendo em vista o permanente estado de aprendizagem. Por isso, repensar a performance na educação remete a potência do sujeito na radicalidade da linguagem como expressão viva de sentido aberto, único e irrepetível que forma, transforma e escapa ao desgaste (fechamento) do tempo. De acordo com Zumthor (2007, p. 48), a performance é concretização (da palavra como ação, gesto, corpo, escuta de sons e imagens) e "prolongamento de um esforço primordial para emancipar a linguagem" de sua função meramente representativa e instrumental, de um tempo do seu esquecimento. Nesse ponto da argumentação, a desterritorialização do conhecimento, a aproximação virtual das pessoas, a interconexão de diálogos globais, as aprendizagens formadas coletivamente e a curiosidade pelo conhecimento constituem efeitos da performance na educação, que geram maneiras inéditas de ser e de estar no mundo.

No cenário contraditório da atualidade, percebemos também a existência de uma forte tendência para a racionalização da educação no que se refere ao saber, às práticas e às instituições, que revela uma escola desconectada, fora do tempo e da fluência tecnológica da sociedade. Para Habermas (1987, p. 202), "o progresso científico pode converter-se em racionalização da vida social se os cientistas assumem a tarefa da educação pública com a finalidade de converter os princípios de seu próprio trabalho em princípios de comércio e trato sociais". Embora os tempos atuais exijam seguidamente uma presença cada vez maior da reflexão filosófica, artística e pedagógica, é notório que esses espaços tem paulatinamente perdido o seu vínculo com a cultura geral. Parece que a aceleração do tempo desestabiliza o empenho ético e a alegria de aprender, pela vigência da temporalidade institucionalmente organizada 
e confundida com a competitividade, que provoca um encolhimento de ações solidárias à construção de uma intersubjetividade democrática. Trata-se, sem dúvida, de um processo em meio ao qual transitamos e que penetra nos espaços educativos da formação, pela ordem das urgências, que significa uma oscilação na razão instrumental. Afinal, como o trabalho do professor e a constituição de seus saberes é mobilizado no tempo? É possível superar a racionalidade estratégica moderna que vincula a imagem da deformação profissional (desqualificação, despolitização)? Esses questionamentos tornam-se ainda mais intrigantes ao constatarmos que "o sujeito moderno, longe de constituir uma essência universal e atemporal é aquilo que foi feito dele. Sua apresentação como essência esconde o processo de sua manufatura" (SILVA, 1995, p. 249). Embora o tempo seja próprio ao campo do desenvolvimento humano, tudo indica que a produção utilitarista e a cegueira do trabalho ${ }^{3}$ tenha contribuído para uma formação desumanizada e de progressiva desvalorização dos professores. Como observa Marx (1974), com a produção que visa tão somente o mercado, dá-se a queda do tempo qualitativo em tempo quantificado, tempo que é reificação da duração, pois se encontra plasmado no presente, o que resulta na perda da qualidade dialética do vivido. $\mathrm{Na}$ trilha dos princípios da lógica capitalista, o trabalho docente recai numa prática alienada em formalidades burocráticas, reduzido à elaboração de relatórios, na quantificação dos objetivos educacionais, pressupondo que o mundo muda de forma ordenada e seguindo uma lógica da superficialidade nos vínculos afetivos (os valores se resumem às vantagens pessoais). A organização institucional do tempo é a figura mais eminente da alienação e da dominação do homem pela lógica da mercadoria, pois os sujeitos perdem o sentido do tempo reflexivo e da própria experiência vital enquanto eticidade de presença no mundo. Há uma percepção geral (abstrata e mecânica) de que os múltiplos sentidos de tempo se entrecruzam nos ritmos definidos pelos cronômetros e calendários, que orientam as atividades rotineiras como uma forma de produzir passividade e progressão. Essa noção de tempo imposta pelo capitalismo tardio aprofunda a crise da identidade profissional do professor e a perda de sentido da ação pedagógica. Essa temporalidade monótona se exprime na ansiedade de ter recursos à disposição e na alienação do significado das ações (automaticidade), atitudes essas que possuem traços da reificação do sujeito. A partir do momento em que o professor se reifica, não há possibilidade de exercício do pensamento, apenas hiperatividade vazia e perda de qualquer sentido da vida. A teoria de Paulo Freire (1996) reconhece que a práxis educativa não é um ato solitário, mas está diretamente ligado à relação com o outro. Por essa razão, impõe-se a necessidade de uma racionalidade performativa para dar conta das necessidades humanas de conhecimento que precisam ser ao mesmo tempo criticadas e reconstruídas.

Segundo Arendt (1966), a tarefa do educador em sua ação é a de inserir os sujeitos no mundo, responsabilizar-se por este mundo e apresentá-lo aos educandos, mesmo sendo o mundo que corrói verdades, desestabiliza valores, valoriza a velocidade e a quantidade de informações. Certamente, a ação educativa apresenta dificuldades em readaptar-se às novas condições.

Podemos responder que na medida em que transformamos nossas práticas em exercícios reflexivos e criativos e estivermos em abertura para a comunicação, tentando não apenas dominar as tecnologias 
virtuais como simples ferramentas, mas como maneiras de ensaiar novas experiências culturais, estaremos participando de um novo tipo de aprendizagem social, a aprendizagem interativa que mimetiza formas reais por meio das virtuais. (MARTINI, 2005, p. 20)

Contudo, a temporalidade contemporânea produz a passagem de um tempo com regras conhecidas a um mundo instável e incerto, cujas transformações exigem argumentos desafiadores da humanidade. A performance virtual ${ }^{4}$ nos coloca diante de possibilidades variadas de ação e de comunicação e assim somos convidados a ver mais, a ouvir mais, a sentir mais globalmente como cidadãos do mundo. Sua temporalidade está diretamente relacionada ao momento de sua apresentação no próprio tempo (manifestação dos sentidos humanos, a audição, a visão, o tato, a emoção, a voz), revolucionando a maneira humana de pensar e agir.

\section{Considerações finais}

Atualmente, a performance se faz presente como fenômeno complexo e integrador de diferentes visões de mundo e tempos de aprendizado, pois tem seu significado a partir da necessidade de responder às mudanças da vida. Neste sentido, há um desafio pedagógico nesta problemática que é de aprender com os outros nas múltiplas possibilidades de interação com o conhecimento, e de transformar as condições de vida daqueles que seguem afetados por problemas sociais. Assim, "no quadro de um processo de entendimento mútuo - virtual ou atual - não há nada que permita decidir a priori quem tem de aprender de quem", visto que a possibilidade contingente e criadora do agir humano habita na linguagem (HABERMAS, 2003, p. 43). Talvez essa capacidade de compreensão resida no fato de nossa razão ser virtualmente linguagem (GADAMER, 1998). A reconstrução comunicativa das estruturas do mundo da vida é o que permite ao professor aprender e validar, numa relação dialogal e intersubjetiva, junto às comunidades cultural, científica e social, as suas expectativas de uma vida melhor, possuindo um telos para o entendimento no campo da formação educativa. Os debates sobre a performance lançam impulsos em nosso tempo, pois apostam no desenvolvimento de processos de aprendizagem reflexivos e críticos, ajudando a acessar o significado da ação educativa que aceita dialogar com a própria condição humana. A performance surge como um campo privilegiado de linguagem e da imaginação criadora, presente em todas as dimensões da formação humana, pois é inevitavelmente o próprio agir dialógico que nos torna transformadores do mundo.

\section{Referências}

ADORNO, T. W. Educação e emancipação. Trad. WOFLGANG, L. M. Rio de Janeiro: Paz e Terra, 1995.

ARENDT, H. A Crise na Educação. In: Entre o passado e o futuro. Barcelona: Península, 1966. 1972.

Entre o passado e o futuro. Trad. ALMEIDA, M. W. B. de. São Paulo: Perspectiva,

ARISTÓTELES. Os Pensadores. São Paulo: Nova Cultural, 1996.

ASSMAN, H. Placer y ternura en educación. Madrid: Narcea, 2002. 
AUSTIN, J. L. Quando dizer é fazer. Porto Alegre: Artes Médicas, 1990.

DEMO, P. Habilidades e competências: no século XXI. Porto Alegre: Mediação, 2010.

DUARTE, R. Dizer o que não se deixa dizer: para uma filosofia da expressão. Chapecó: Argos, 2008.

FREIRE, P. Pedagogia da autonomia: saberes necessários à prática educativa. São Paulo: Paz e Terra, 1996.

GADAMER, H. G. Verdade e método: traços fundamentais de uma hermenêutica filosófica. Trad. MEURER, F. P. 2. ed. Petrópolis: Vozes, 1998.

La educación es educarse. Trad. BLASI F. P. Barcelona: Paidós Ibérica, 2000.

GAUTHIER, C. (et al.). Por uma teoria da pedagogia: pesquisas contemporâneas sobre o saber docente. Trad. PEREIRA, F. 2. ed. Ijuí: Ed. Unijuí, 2006.

HABERMAS, J. Consciência moral e agir comunicativo. Trad. ALMEIDA, G. A. de. Rio de Janeiro: Tempo Brasileiro, 2003.

. Agir comunicativo e razão destranscendentalizada. Trad. ARAGÃO, L. Rio de Janeiro: Tempo Brasileiro, 2002.

Teoría de la acción comunicativa, I: Racionalidad de la Acción y Racionalización Social. Traducción de REDONDO, M.J. 4.ed. Madrid: Taurus, 1987.

Teoria de la acción comunicativa: complementos y estudios previos. Traducción de REDONDO, M.J. Madrid: Cátedra, 1989.

. La lógica de las ciências sociales. 3. ed. Madrid : Tecnos, 1996.

Pensamento pós-metafísico: estudos filosóficos. Tradução de SIEBENEICHLER, F. B. Rio de Janeiro: Tempo Brasileiro, 1990.

Verdade e justificação: ensaios filosóficos. Tradução de MOTA, M. C. São Paulo: Loyola, 2004. 1999.

. Teoría de la acción comunicativa II: crítica de la Razón Funcionalista. Madrid: Taurus,

HERMANN, N. Pluralidade e ética na educação. Rio de Janeiro: DP\&A, 2001.

Ética e estética: a relação quase esquecida. Porto Alegre: EDIPUCRS, 2005.

LÉVY, P. As tecnologias da inteligência: o futuro do pensamento na era da informática. Rio de Janeiro: Editora 34, 1993.

LIPOVETSKY, G. ; CHARLES, S. Os tempos hipermodernos. São Paulo: Barcarolla, 2004.

MARTINI, R. M. F. Mundo da vida, diálogo e crítica: em busca de atalhos para um encontro entre Habermas e Paulo Freire. In: SILVEIRA, F. T; GHIGGI, G; PITANO, S. C. (Orgs.) Leituras de Paulo Freire: contribuições para o debate pedagógico contemporâneo. Pelotas: Seiva Publicações, 2007, p. 261- 280

. Reencantar a ação educativa, um empreendimento possível? In: Reflexão e Ação. Santa Cruz do Sul: EDUNISC, v. 13, n. 2, jul./dez. 2005, p. 15-21.

MARX, K. Salário, preço e lucro. In: CIVITA, V. (Ed.). Os Pensadores. Karl Marx. São Paulo: Abril Cultural, 1974.

MOURA, R. S. de. A experiência do 'tempo do agora', educação e reconhecimento social [manuscrito]. Porto Alegre: UFRGS, 2007.

NÓVOA, A. Relação escola-sociedade: novas respostas para um velho problema. In: SERBINO, R. et al. Formação de professores. São Paulo: UNESP, 1996. 
RICOEUR, P. Introdução. In UNESCO (Org.). As culturas e o tempo. Petrópolis: Vozes, 1975.

ROHDEN, L. Hermenêutica filosófica: entre a linguagem da experiência e a experiência da linguagem. São Leopoldo: Editora da UNISINOS, 2002.

SILVA, T. T. O projeto educacional moderno: identidade terminal? In: VEIGA-TARDIF, M. Saberes docentes e formação profissional. Petrópolis: Vozes, 2002.

TARDIF, M.; LESSARD, C. O trabalho docente: elementos para uma teoria da docência como profissão de interações humanas. Trad. KREUCH, J. B. Petrópolis: Vozes, 2005.

ZUMTHOR, P. Performance, recepção e leitura. Trad. FERREIRA, J. P.; FENERICH, S. São Paulo: Cosac Naify, 2007.

\section{Notas}

${ }^{1}$ Piscitelli (2002) introduz as tecnologias como todas aquelas conversaçôes que ocorrem nas conexões com o mundo, nas quais inventamos novas práticas de ser no mundo e novas ferramentas para conduzir as organizações e a vida humana.

${ }^{2}$ A interação face a face é definida por Goffman (1975, p. 23) “como a influência recíproca dos indivíduos sobre as ações uns dos outros, quando em presença física imediata. O termo encontro também seria apropriado. Um desempenho pode ser definido como toda atividade de um determinado participante, em dada ocasião, que sirva para influenciar, de algum modo, qualquer um dos outros participantes". Afinal, o mundo é um teatro e cada um de nós é ator, que realiza uma atividade e dá um espetáculo para benefício de outros.

${ }^{3}$ Para Adorno (1995), o trabalho e o lazer (tempo livre) são duas faces da mesma moeda, pois tanto o trabalho quanto o lazer passam a valer dinheiro, de acordo com a dinâmica da participação e subordinação à organização social segundo o regime de lucro. A relação humana transformada em mercadoria gera a semiformação, semieducação, semicultura e semicidadania, alterando-se por esta via a própria noção de trabalho educativo.

${ }^{4} \mathrm{O}$ virtual deriva da palavra virtus que podemos traduzir como força, potência, atualização. Para Lévy (1993), o virtual não seria o oposto do real, mas outra configuração do real, já que não se trata de eleger entre a nostalgia de um real fechado e um virtual ameaçador ou excitante, e sim entre diferentes concepções do virtua

\section{* Professora Doutora do Centro Universitário La Salle, Canoas, Rio Grande do Sul, Brasil.}

\section{Correspondência}

Elaine Conte - Rua São Vicente, 32/302, Bairro Rio Branco, Porto Alegre - Rio Grande do Sul. CEP: 90630-180, Brasil.

E-mail: elaineconte@yahoo.com.br

Recebido em 20 de abril de 2014

Aprovado em 04 de agosto de 2014 